\title{
Vom Umgang mit biblischen Texten in antisemitischen Kontexten
}

\author{
Tobias Nicklas ${ }^{1}$ \\ Universität Regensburg \\ Deutschland
}

\begin{abstract}
The Bible in anti-Semitic contexts

The article focuses on the (ab-)use of New Testament texts in the time of National Socialism. After a definition of central terms, it describes how anti-Semitic authors interpreted biblical texts. It then presents an overview of authors who attempted to prove Jesus' Aryan origins and anti-Jewish position (e g, the so-called "Pantherathesis"). After explaining how (and why) Paul is seen as "too Jewish" by Third Reich scholars, the article investigates the continuing influence of Nazi exegesis and concludes with an overview of recent developments regarding this issue.
\end{abstract}

\section{EINLEITUNG}

Das Thema „Bibel“ und „Gewalt" kann von verschiedenen Dimensionen aus betrachtet werden. So ist zunächst sicherlich die Frage zu stellen, wie mit biblischen Texten, in denen Gewalt eine Rolle spielt bzw. in denen auf gewalttätige Weise etwa mit Gegnern umgegangen wird, umzugehen ist, ja vielleicht. Andererseits aber wäre es naiv zu glauben, dass wir - als von unserer Umwelt, unserer kulturellen, sozialen, vor allem aber auch geschichtlichen Prägung unbeeinflusst - heute einfach einen direkten, vielleicht gar objektiven Zugang zu den Texten bekommen könnten. Um die Traditionen, in denen unser Verständnis biblischer Texte steht (oder von denen es sich bewusst wie unbewusst abzusetzen sucht) zu verstehen, ist somit auch die Aufarbeitung der Auslegungsgeschichte biblischer Texte nötig. Wo aber wirklich auslegungsgeschichtlich gearbeitet wird, genügt es nicht einfach, mehr oder minder katenenartig Interpretationen früherer Zeiten

\footnotetext{
${ }^{1}$ Prof Dr Tobias Nicklas (Universität Regensburg) is a registered research associate of Prof Dr Jan G van der Watt, Department of New Testament Studies, Faculty of Theology,

University of Pretoria.
} 
nebeneinander zu stellen. Vielmehr ist es nötig, Auslegungen biblischer Texte mit den jeweiligen historischen Kontexten, in denen sie standen und auf die sie wirkten, in Verbindung zu setzen. Eine derart verstandene Rezeptionsoder Auslegungsgeschichte biblischer Texte ist so auch von einer biblischen Wirkungsgeschichte nicht ganz zu trennen.

An einem Beispiel, in dem besonders signifikant ein von verschiedensten Dimensionen der Gewalt geprägter historischer - zunächst einmal geistesgeschichtlicher, dann aber Gesellschaften auf verschiedensten Ebenen prägender - Kontext erheblichen Einfluss auf die Auslegung biblischer Texte gewann, möchte ich die Bedeutung dieser zweiten Dimension der Fragestellung „Neues Testament“ und „Gewalt“ aufzeigen:

Zumindest auf den ersten Blick scheinen „Bibel“ und „Antisemitismus“ nichts miteinander zu tun zu haben: Was kann die Bibel mit Antisemitismus zu tun haben, wenn doch ihr erster Teil, das Alte Testament, von der Heilsgeschichte des Volkes Israel spricht, und die Protagonisten ihres zweiten Teils, des Neuen Testaments, also Jesus von Nazaret, seine Jünger, aber auch Paulus, samt und sonders Juden waren (und wohl ihr gesamtes Leben lang blieben)? Immerhin besteht zu Recht seit Jahrzehnten eine ausführliche Debatte, ob und inwiefern manche Passagen vor allem des Neuen Testaments antijüdisch seien oder antijüdische Interpretationen zuließen. ${ }^{2}$ Ich denke in diesem Zusammenhang vor allem an 1 Thess 2, 15-16; Joh 8, 44 oder Mt 23 oder 27, 25 - die Reihe ließe sich aber durchaus fortsetzen. Ich denke auch an die polemische Verwendung biblischer Passagen in antijüdischen Predigten oder Traktaten der Antike - besonders bekannt sind Texte wie der Barnabasbrief, Melito von Sardes' Predigt „Über das Pascha“ oder Johannes Chrysostomus' Homilien „Gegen die Juden“ - und auch diese Reihe ließe sich natürlich fortsetzen.

Doch darum geht es mir nicht: Zumindest im deutschen Sprachgebrauch sind die Begriffe „Antijudaismus“3 und „Antisemitismus“ nämlich voneinander zu differenzieren: Während üblicherweise von

\footnotetext{
${ }^{2}$ Die Literatur zu diesem Thema ist inzwischen beinahe unüberschaubar. Weiterführend sind z.B. Kampling (1999) sowie Bieringer (2001).

${ }^{3}$ Eine brauchbare Definition des Begriffs „Antijudaismus“ geht auf Thomas (1997:9), zurück, der schreibt: „Unter Antijudaismus ... versteht man eine apriori generalisierende, auf öffentliche Agitation und Pogrome zielende Feindschaft gegen Juden, weil sie zum jüdischen Volk und zu dessen Geschichte und Religion gehören. Dabei wird nicht oder nur in verfälschter Weise auf die historische Wahrheit und die Situation einzelner Juden Rücksicht genommen. In seinem Kern ist der Antijudaismus eine von Vorurteilen genährte Entfremdung des nichtjüdischen vom jüdischen Menschen und dessen anderer Lebensart, Religion und Tradition." Eine Reihe weiterer Definitionen diskutiert Kraus (1997:22-24). Vos (1984:89-90) unterscheidet zudem zwischen „theologischem" und „exegetischem Antijudaismus“, der dann zudem noch von „Antisemitismus" zu trennen sei. Dies erscheint mir, wie sich dann auch im Verlauf der Studie immer wieder zeigt, doch als etwas künstlich.
} 
Antijudaismus gesprochen wird, wenn religiöse Motive zum Judenhass führen, sollte von „Antisemitismus“ erst dann die Rede sein, wo Judenhass mit nationalistischen, ökonomischen, vor allem aber rassentheoretischen Ideen begründet wird. Sicherlich lassen sich beide Phänomene nicht vollkommen trennscharf voneinander unterscheiden, trotzdem kann vom "Antisemitismus“ (oder gar „Rassenantisemitismus“) im engeren Sinne erst mit dem 19. Jahrhundert gesprochen werden. ${ }^{4}$ Damit eng zusammen hängt ein weiteres Phänomen: Interessanterweise kam es im Deutschland des 19., vor allem aber des frühen 20. Jahrhunderts mit der Entstehung eines „arischen Christentums“ zu einer eigenartigen Verbindung von rassentheoretisch begründetem Antisemitismus und Religion, ein Phänomen, das von Saul Friedländer als „Erlösungsantisemitismus“ bezeichnet wird. ${ }^{5}$ Vor allem ein Aspekt dieser Erscheinung soll im Zentrum des folgenden Beitrags stehen: die Interpretation - oder besser: der Missbrauch - biblischer Texte zur ideologischen Untermauerung eines „arischen“ bzw. „deutschen Christentums."6

Das Thema des folgenden Beitrags lässt sich also folgendermaßen präzisieren: Inwiefern wurden biblische Texte vor allem des Neuen Testaments vor dem Hintergrund antisemitischer Ideologien, zur Unterstützung antisemitischen Gedankenguts oder im Rahmen antisemitischer Propaganda missbraucht? Der vorliegende Rahmen erlaubt natürlich keineswegs Vollständigkeit; er lässt zudem auch einen alle historischen Entwicklungslinien nachzeichnenden Überblick kaum als sinnvoll erscheinen. $^{7}$

Ich möchte im Folgenden einen anderen Zugang wählen und auf typische, immer wieder begegnende Motive hinweisen, die sich in antisemitisch motivierter Exegese vor allem im Umfeld des Nationalsozialismus entdecken lassen und die sich aber - fatalerweise - dann immer wieder als stereotyp wiederholte Aussagen auch bei Autoren wiederfinden, denen keineswegs eine antijüdische oder antisemitische

\footnotetext{
${ }^{4}$ Der Begriff wurde tatsächlich auch erst im 19. Jahrhundert geprägt. Er dürfte auf Wilhelm Marr zurückgehen. Weiterführend vgl. Zimmermann (1986). Die hier vorgenommenen Unterscheidungen aber lassen sich in der Praxis nicht immer durchhalten. Vor allem leben auch antisemitische Aussagen des 19. und 20. Jahrhunderts in vielen Fällen von antijüdische Stereotypen aufgegriffen wurden, die sich z.T. bis in die Antike zurückverfolgen lassen - ihre Verbindung mit Rassenideologien verleiht diesen Stereotypen aber eine neue Qualität. Zur Geschichte des Antisemitismus in Deutschland vgl. Greive (1988).

${ }^{5}$ Friedländer (1998:101).

${ }^{6}$ Zu den „Deutschen Christen“ als Bewegung vgl. Bergen (1996) sowie Meier (2001).

${ }^{7}$ Einen solchen hat zumindest für den Aspekt der „Arisierung“ Jesu Fenske (2005) vorgelegt. Das umfassende Material, das in diesem Band zusammengetragen ist, soll auch im Folgenden regelmäßig herangezogen werden. Zudem findet sich dort auch eine Vielzahl weiterer Informationen, die hier nicht dargestellt werden können. Wichtig ist auch Head (2004).
} 
Haltung vorgeworfen werden kann. Besonders gefährlich aber wird es, wenn solche Stereotypen sich in breiteren kirchlichen und gesellschaftlichen Kreisen durchsetzen - sie dann noch zu durchbrechen, kostet ungeheuere Mühen und Anstrengungen.

\section{GRUNDKONSTELLATIONEN}

Eine in verschiedenen Variationen zu beobachtende Grundkonstellation antisemitisch motivierter Exegese beruht häufig auf den folgenden Eckpfeilern, aus denen sich dann weitere Ableitungen ergeben: eine Distanzierung Jesu von Nazaret vom Judentum, die verschiedene Formen annehmen kann:

- In der extremsten Form wird versucht, Jesu „arische“ Herkunft beweisen zu wollen;

- $\quad$ in anderen Fällen wird Jesus zumindest vom Judentum seiner Zeit abgegrenzt und versucht, wenigstens Teile des Alten Testaments zu retten.

In beiden Fällen geht damit eine pauschale Abwertung des Judentums der Zeit Jesu als „Spätjudentum“ einher. Im Falle des zweiten Punktes lassen sich die folgenden Differenzierungen beobachten: Abwertung jüdischer Literatur ab der Periode des Zweiten Tempels, wobei besonders apokalyptische Literatur gerne als eschatologische Schwärmerei ohne Offenbarungsbezug abgetan wird, ${ }^{8}$ und Erstellung des historischen Zerrbilds einer angeblichen pharisäisch-rabbinischen Schreckensherrschaft, die geradezu totalitäre Züge angenommen habe. ${ }^{9}$ Dies verbindet sich immer wieder mit der Vorstellung, *bereits das antike Judentum habe mit den verschiedensten Mitteln versucht, die Weltherrschaft zu erobern. ${ }^{10}$ Diesem „Judentum“ der Zeit Jesu wird dann die alleinige Schuld an der Hinrichtung Jesu zugeschrieben, die Rolle des Pilatus dagegen wird zurückgedrängt. Dass in solchen Argumentationen

\footnotetext{
${ }^{8}$ Zur Kritik am Apokalyptik-Bild der „Spätjudentums“-Theorie vgl. Müller, (1991:38-40).

${ }^{9}$ So schreckt noch 1982 Stauffer (1982:99-100 n. 797) nicht einmal davor zurück, den jüdisch-pharisäischen „Polizeiapparat“ mit Geheimdiensten moderner totalitärer Systeme u.a. des Nationalsozialismus - zu vergleichen. Vgl. auch die Darstellung des Pharisäismus in dem noch 1989 wiederaufgelegten Werk Hirschs (1989:54-55).

${ }^{10}$ Ein solches Extrembeispiel ist etwa Bertram $(1940,1943)$. Gerade im zweiten Text fallen Sätze wie: „Um die Wende der Zeiten war das Judentum im Begriff, politisch, wirtschaftlich und geistig die Welt zu erobern. Von ihrem abseits gelegenen Machtsitz Jerusalem aus arbeitete die jüdische Priesterschaft an der Unterwerfung der Völker ... Zwar erwartete man auch die politische Herrschaft keineswegs nur vom Wunder der Zukunft. Man arbeitete vielmehr mit allen Mitteln darauf hin. Und gerade die indirekte Methode der geistigen und wirtschaftlichen Beeinflussung der führenden Schichten in der hellenistischen Welt hat zu überraschenden Erfolgen geführt“ (1943:85).
} 
frühjüdische und rabbinische Quellen nicht in angemessener Weise berücksichtigt werden, sondern man diese Texte nur in Auszügen, ohne genauere Rückfrage auf ihre historische Einordnung, Plausibilität und Aussagekraft zur Unterstützung pauschaler Urteile heranzieht, geht damit einher.

Mit der Distanzierung Jesu vom Judentum stellt sich aber ein theologisches Problem ein: Im Grunde muss Jesus damit auch von den Heiligen Schriften Israels, dem Alten Testament, distanziert werden. Dies geschieht auf unterschiedliche Weise: ${ }^{11}$

- mit Hilfe einer pauschalen Abwertung des Alten Testaments als eines Textes, in dem sich ein dunkles Gottesbild offenbare, ${ }^{12}$ das nichts mit dem wahren Gott, der sich im Neuen Testament zu erkennen gibt, zu tun habe;

- mit Hilfe einer meist strikten Trennung zwischen vor- und nachexilischem Judentum;

- über die Feststellung zweier Strömungen im Alten Testament - eines angeblich ,jüdischen“ Teils, der abgewertet wird, sowie eines angeblich am Judentum und seiner Religionsausübung kritischen Teils; während die Tora meist als Beispiel für die erste Richtung angesehen wird, werden prophetische Texte gerne der zweiten Strömung zugeordnet.

Die erste dieser „Lösungen“ beschäftigt das Christentum im Grunde seit Marcion. Fatalerweise wurde ihr im frühen 20. Jahrhundert nicht nur durch bekennende Antisemiten, sondern auch durch Autoren wie den bedeutenden Kirchenhistoriker Adolph von Harnack eine gewichtige (und immer wieder

\footnotetext{
${ }^{11}$ Weiterführend zu geschichtlichen Entwicklungen und den Positionen einzelner Autoren vgl. Nicolaisen (1966) und Kusche (1991).

${ }^{12}$ In diesem Zusammenhang wichtig ist z.B. der Assyriologe Friedrich Delitzsch (1850-1922), der bereits in seinen „Bibel und Babel“-Vorträgen um die Wende zum 20. Jahrhundert den Wert des Alten Testaments zu relativieren suchte, v.a. aber in seinem Buch „Die große Täuschung" - beeinflusst durch antisemitische Autoren wie P. de Lagarde und H.S. Chamberlain - das Alte Testament als Glaubensurkunde völlig ablehnte. So schreibt er etwa: Die „Erforschung des althebräischen Schrifttums, das uns Gottes Wesen und Walten so wenig offenbart als es vielmehr von Anfang bis zum Ende das Spiegelbild eines engherzigsten und zugleich unwürdigsten Gottesbegriffs ist, sollte deshalb auch nicht länger einen Zweig der christlichen Theologie, sondern besser der orientalischen Philologie und allgemeinen Religionsgeschichte überlassen werden“ (Delitzsch [1921] 1924:97).
} 
zitierte) Stimme verliehen. ${ }^{13}$ Ihre schlimmsten Auswüchse finden sich etwa in den Werken eines der Chefideologen des Nationalsozialismus, Alfred Rosenberg (1893-1946), ${ }^{14}$ der in seinem in über einer Million Exemplaren verkauften Werk „Der Mythus des 20. Jahrhunderts“ forderte, das Alte Testament abzuschaffen, damit endlich „der mißlungene Versuch der letzten anderthalb Jahrtausende, uns geistig zu Juden zu machen," entfalle. An die Stelle „der alttestamentlichen Zuhälter- und Viehhändlergeschichten“ sollten „die nordischen Sagen und Märchen treten, anfangs schlicht erzählt, später als Symbole begriffen. " ${ }^{15}$

Die zweite, deutlich gemäßigtere Variante verbindet sich mit der Vorstellung einer Entfernung Israels von seiner ursprünglichen Offenbarung, seiner angeblichen Entwicklung zum Spätjudentum bzw. rabbinischen Judentum, wobei meist eine entscheidende Trennlinie zwischen „Israel“ und „Judentum“ in der Zeit des Exils gesehen wird. ${ }^{16}$ Diese Variante erlaubt immerhin noch die Vorstellung, Jesus sei ein Jude gewesen, habe sich aber in seinem Denken von seinen Zeitgenossen deutlich unterschieden, sondern am vorexilischen Judentum angeknüpft. ${ }^{17}$

Die Theorie von zwei unterschiedlichen Strömungen im Alten Testament schließlich konnte sich auf verschiedene Weise äußern. ${ }^{18}$ Man

\footnotetext{
${ }^{13}$ Vgl. v.a. Harnack (1924:217): „Das Alte Testament im 2. Jahrhundert zu verwerfen, war ein Fehler, den die große Kirche mit Recht abgelehnt hat; es im 16. Jahrhundert beizubehalten, war ein Schicksal, dem sich die Reformation noch nicht zu entziehen vermochte; es aber im 19. Jahrhundert als kanonische Urkunde im Protestantismus noch zu konservieren, ist die Folge einer religiösen und kirchlichen Lähmung." Harnack lehnte das Alte Testament aufgrund seiner Vorstellung einer Entwicklung der Erkenntnis der Wahrheit in der Geschichte als kanonische Schrift ab. Allerdings solle es weiterhin als „gut und nützlich zu lesen“ (1924:223) anerkannt bleiben. Dass derartige Aussagen eines so anerkannten Wissenschaftlers wie von Harnack Wasser auf die Mühlen antisemitischer Autoren war, versteht sich von selbst.
}

${ }^{14}$ Der 1893 in Reval (Estland) geborene Rosenberg trat bereits 1919/20 der späteren NSDAP bei, wurde zum Hauptschriftleiter des „Völkischen Beobachters" und saß ab 1930 als Abgeordneter der NSDAP im deutschen Reichstag, ab 1933 war er Reichsleiter im außenpolitischen Amt der NSDAP, ab 1941 Minister für die besetzten Ostgebiete; 1946 wurde er wegen „Verbrechen gegen die Menschlichkeit“ zum Tode verurteilt und hingerichtet. Weiterführend Poliakov \& Wulf (1959) sowie Head (2004:68-70).

${ }^{15}$ Die beiden Zitate stammen aus Rosenberg ([1930] 1941:603, 614).

${ }^{16}$ Entscheidende Gedanken finden sich schon bei de Wette (1813). Besonders einflussreich dürften in diesem Zusammenhang vor allem die Arbeiten eines der Begründer historischkritischer Exegese des Alten Testaments, Julius Wellhausen (1844-1918), gewesen sein: Zu Wellhausens Darstellung der Geschichte Israels vgl. v.a. Kusche (1991:30-74).

${ }^{17}$ So z.B. Kittel (1929: 202), der diese Vorstellungen dann mit der Idee verbinden konnte, Jesus habe an das vorexilische Judentum angeknüpft.

\footnotetext{
${ }^{18}$ Vgl. Fenske (2005:194). Vgl. auch den Exkurs des Autors zum Thema (2005:194-198). Interessant hierzu sind auch die Ausführungen von Nicolaisen (1966:32-39) (Max Maurenbrecher, Wilhelm Stapel) sowie (1966:47-55) (die Verteidigung des AT bei Johannes Hempel, Ernst Sellin und Friedrich Baumgärtel). Zu Ernst Sellin vgl. darüber hinaus Kusche (1991:146-162).
} 
sprach von einer Unterscheidung zwischen „Israelitismus“ und „Judentum“, unterschied zwischen göttlicher Offenbarung und volkstümlichem Denken, oder betonte das Gegenüber der Propheten zum jüdischen Volk. ${ }^{19}$

Auch unter den frühchristlichen Quellen muss dann natürlich eine Gewichtung vorgenommen werden - Texte, die den jüdischen Jesus zeichnen, werden dann gerne abgewertet: Das noch stark jüdisch geprägte früheste Christentum habe das religiöse Genie Jesus von Nazaret nur äußerst unzureichend verstanden - so mancher Autor geht so weit zu behaupten, ein angemessenes Verstehen Jesu sei letztlich erst in einem „arischen“germanischen-Kontext möglich gewesen. Dabei wurde überraschenderweise von einigen Autoren das (heute immer wieder für seine antijüdischen Potentiale kritisierte) Matthäusevangelium abgewiesen, weil es Jesus zu sehr „rejudaisiere“, ${ }^{20}$ während das Johannesevangelium gerne in den Mittelpunkt des Interesses rückte. So schrieb etwa der bereits genannte Alfred Rosenberg: In seinem Kampf gegen die „Verbastardierung, Verorientalisierung und Verjudung des Christentums" atme das Johannesevangelium „durchaus noch aristokratischen Geist“ ${ }^{21}$ während Artur Dinter (1876-1948) ${ }^{22}$ bereits 1922 so weit ging, das Johannesevangelium als die „gewaltigste antisemitische Schrift, die jemals geschrieben worden ist," zu bezeichnen. ${ }^{23}$

\section{JESUS ,DER ARIER“}

In seinem 1906 in erster sowie 1913 in zweiter Auflage erschienenen Buch Geschichte der Leben-Jesu-Forschung zeigt Albert Schweitzer, dass die großen Jesusbiographien des 19. Jahrhunderts in vielen Fällen weniger über den historischen Jesus als über die Ideale des jeweiligen Autors, der sie

\footnotetext{
${ }^{19}$ Mit dieser Vorstellung setzt sich auch Pohlmann (1943) auseinander - einer Meinung nach geht diese Lösung nicht weit genug; Jesu Gottesbild unterscheide sich fundamental auch von dem der Propheten Israels.

${ }^{20}$ So suchte noch im Jahr 1982 der protestantische Neutestamentler Ethelbert Stauffer das Matthäusevangelium für alle späteren kirchlichen Fehlentwicklungen verantwortlich zu machen. Er schreibt: „Jesus erscheint in der Bergpredigt als der Superpharisäer, der die pharisäische Extrafrömmigkeit noch übertrumpft. Die Tendenz ist unverkennbar: Mt zeichnet ein rejudaisiertes Jesusbild, um den Juden ein Jude zu werden." Vgl. Stauffer (1982:15).

${ }^{21}$ Rosenberg ([1930] 1941).

${ }^{22}$ Zu Dinter vgl. Fenske (2005: 132): Dinter „gehörte früh dem Kreis um Hitler an. Seit 1923 Gauleiter in Thüringen, 1928 von Hitler aus der Partei ausgeschlossen, da er versucht habe, die Partei in seine religiöse Richtung zu drängen. ... Von der Partei als religiöser Konkurrent in seiner Tätigkeit behindert. Nach Kriegsende wurde er im Rahmen des

Entnazifizierungsverfahrens als ,intellektueller Urheber der Nürnberger Rassegesetze، verurteilt." Weiterführend vgl. Schulz \& Wolfes (2001).

${ }^{23}$ Dinter (1922:92). Bekanntlich spielte auch die Offenbarung des Johannes - z B mit ihrem Bild vom "Tausendjährigen Reich" eine Rolle in nationalsozialistischem Verständnis des Neuen Testaments (z.B. bei J. Goebbels). Hierzu weiterführend v.a. Bärsch (1988).
} 


\section{Vom Umgang mit biblischen Texten in antisemitischen Kontexten}

verfasste, sagen (vgl. Schweitzer 1984). Die Autoren der „Leben-JesuForschung" hätten weniger ein „objektives Bild“ des historischen Jesus gezeichnet als (mehr oder weniger unbewusst) sich selbst in ihr Bild Jesu hineinprojiziert. Wie wir heute wissen, steckt in Schweitzers Entdeckungen ein Kern, der nicht nur auf die von inm kritisierten Arbeiten des 19. Jahrhunderts bezogen werden kann, sondern der von bleibender, grundsätzlicher Gültigkeit ist: Die Unerreichbarkeit der Vergangenheit, die nur über selektierende sowie ebenfalls aus subjektiver Perspektive verfasste Quellen in Ansätzen gespiegelt wird, macht es unmöglich, „Geschichte“ objektiv zu rekonstruieren. Zunächst müssen die vorhandenen Quellen methodisch einwandfrei daraufhin untersucht werden, inwiefern sie „Fakten“ spiegeln. Die Fakten wiederum machen alleine noch nicht "Geschichte" aus. Diese kann erst dann „konstruiert“ werden, wo „Fakten“ miteinander sinnvoll verbunden und interpretiert werden. In diesem Prozess spielt der Interpret natürlich immer eine Rolle. Dies heißt, dass es niemals eine vollkommen „objektive“ Darstellung des historischen Jesus von Nazaret geben wird. Dies heißt aber nicht, dass der historisch arbeitende Wissenschaftler damit aus seiner Verantwortung entlassen würde oder dass es keine „Grenzen der Interpretation“ des Materials gebe. Überall, wo die Aussagen der Quellen zurücktreten, wo methodisch unsauber oder verantwortungslos mit innen umgegangen wird, vor allem aber wo sie nur noch im Hinblick auf eine vom Interpreten vertretene Ideologie missbraucht werden, sind diese Grenzen sicherlich überschritten. Die Arbeit des Historikers ist so immer eine Gratwanderung, die dauernde höchste Selbstreflexion erfordert. Gerade aber bei einer Gestalt wie Jesus von Nazaret, an deren Beurteilung sich nicht nur „der" christliche Glaube an sich entscheidet, sondern mit der Jahrhunderte alte Gräben zwischen Konfessionen und die verschiedensten Möglichkeiten der Ideologisierung zusammenhängen, ist die Verantwortung des historisch arbeitenden Theologen besonders groß - besonders gro $ß$ aber gleichzeitig auch die Gefahr der ideologischen Vereinnahmung. ${ }^{24}$ Wie weit die Gefahren einer derartigen Überschreitung der "Grenzen der Interpretation“ (U. Eco) gehen können, zeigt sich am Beispiel der Versuche, Jesus von seiner jüdischen Herkunft abzulösen, um inn für ein „deutsches Christentum“ vor dem Hintergrund nationalsozialistischer Ideologien annehmbar zu machen.

Die extremsten Versuche, Jesus und das Judentum voneinander zu trennen, gingen so weit, die jüdische Herkunft Jesu vollkommen abzustreiten und seine angebliche arische Herkunft zu beweisen. Dafür aber mussten verschiedene, methodisch unhaltbare „Kunstgriffe“ angewandt werden, die sich miteinander verbinden können:

\footnotetext{
${ }^{24}$ Einen Überblick über die verschiedensten Auswüchse jüngerer Jesusliteratur bietet z.B. Fenske (1999).
} 
1. Bereits auf das 19. Jahrhundert geht die Idee zweier „Rasse“Strömungen im Judentum zurück, eine Fortführung der oben genannten Vorstellung von den zwei Strömungen im Alten Testament: ${ }^{25}$ Dabei wurde die These vertreten, bereits vor den Juden seien in Israel Arier bzw. Germanen ansässig gewesen. Dies wiederum erlaubte einerseits, wenigstens in Teilen des Alten Testaments „arisches“ Denken zu entdecken, sowie andererseits Jesus als Arier zu denken, der von seinen jüdischen Zeitgenossen missverstanden (aber Jahrhunderte später von „Ariern“ wie Meister Eckhard oder Martin Luther in seiner wahren Bedeutung wiederentdeckt) wurde.

2. Sehr gerne wird die galiläische Herkunft Jesu von Nazaret zum Ausgangspunkt der Argumentation gemacht: Der Landstrich Galiläa sei weitestgehend heidnisch geprägt, im besten Falle „zwangsjudaisiert“, und bei der Urbevölkerung, der auch Jesu Eltern angehörten, habe es sich um arische Galater gehandelt. Bereits Ernest Renans berühmtes und einflussreiches „Leben Jesu“ (1863) geht davon aus, dass in Galiläa im Grunde ein Gemisch verschiedener Völker lebte, ${ }^{26}$ während Hermann Freiherr von Soden (1852-1914) zwar schrieb, dass das Galiläa der Zeit Jesu „noch vielleicht zur Hälfte von Nichtjuden bewohnt“"war, aber damit keine eindeutige Aussage zu Jesu Abstammung verknüpfte. ${ }^{27}$ Der langjährige Dekan der Göttinger Theologischen Fakultät (1933-1945), Emmanuel Hirsch, ging im Jahr 1939 noch einen deutlichen Schritt weiter: „[D]ie Wahrscheinlichkeit für einen Galiläer zur Zeit Jesu, daß er nicht einen Tropfen jüdischen Bluts in sich hat, muß auf 9 zu 1 geschätzt werden.. "28 Dass für derartige Zahlen keinerlei Belege angegeben werden, versteht sich von selbst.

\footnotetext{
${ }^{25}$ Vgl. hierzu Fenske (2005:32 und 194-198).

${ }^{26}$ Vgl. Renan (1981 [1863]). Renans Freund, der Göttinger Orientalist Paul de Lagarde, sprach von dem „verhältnismäßig gesunden Galiläa“ (1886:305) und meinte damit, dass der Landstrich freier von jüdischem Einfluss als Judäa gewesen sei. Bereits die Tatsache, dass Renans Werk mit seiner Negativdarstellung eines Judentums, von dem Jesus so weit wie möglich abgegrenzt wird (ohne inn allerdings zum Arier zu machen), noch im Jahr 1981 eine deutschsprachige Neuauflage erlebte, zeigt die ungeheuere Nachwirkung dieses Buches.

${ }^{27}$ Von Soden (1909:113-114). Dieser Text war mir im Original nicht zugänglich; ich zitiere nach Fenske (2005:124).

${ }^{28}$ Hirsch (1939); Fenske (2005:226). Ähnliche Aussagen finden sich etwa auch bei Grundmann, Jesus (1940:169-170). Noch weiter geht H. Weidemann, Bischof von Bremen, in seinem „Evangelium Johannes Deutsch“ (Bremen 1936), wo diese Theorien bis in den Text des Evangeliums (Joh 1, 45-46) eingetragen werden. Hierzu weiterführend Head (2004:8081).
} 
3. Um zu beweisen, dass der Vater (bzw. Großvater) Jesu keineswegs Jude, sondern griechischer Herkunft gewesen sei, wird zudem immer wieder die obskure „Panthera-Tradition“ herangezogen. ${ }^{29}$ Eine Möglichkeit, einen arischen Jesus zu „konstruieren“, besteht im Rückgriff auf die so genannte „Panthera“-Tradition: In seiner Schrift Contra Celsum zitiert Origenes den wohl ältesten bekannten Beleg für die Tradition, Jesus sei das uneheliche Kind eines Soldaten namens

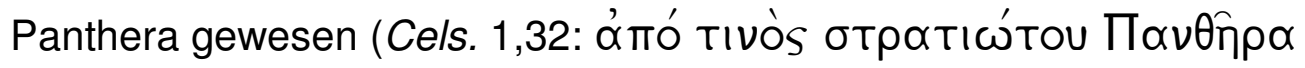

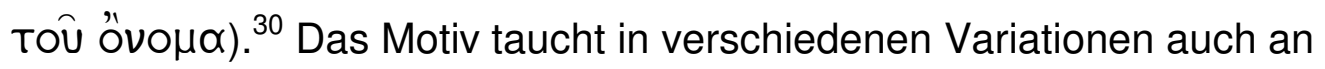
einigen Stellen in rabbinischer Literatur und schließlich im jüdischen „Anti-Evangelium“, den Toledot Jeschu, wieder auf. ${ }^{31}$ Die Herkunft dieses Motivs ist unklar - womöglich liegt hier ein Wortspiel zwischen

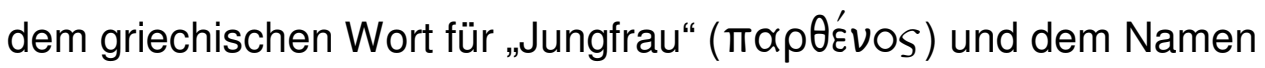
des angeblichen Vaters Jesu (in den Texten $\pi \alpha ́ v \theta \varepsilon \rho \rho$ oder $\pi \propto \nu \theta \hat{p} \rho \alpha)$ vor. ${ }^{32}$ Was aber in diesen späten Quellen mit dem Ziel geäußert wird, bereits die Umstände von Jesu Geburt in möglichst hohem Maße zu verunglimpfen, wird in Kreisen, die einen jüdischen Jesus nicht akzeptieren wollen, sondern denen es um eine „Arisierung Jesu" geht, aufgegriffen und zu begründen gesucht. So überlegte schon in der Mittel des 19. Jahrhunderts Georg Lommel, Jesus sei aus einem Verhältnis Mariens mit einem römischen Soldaten hervorgegangen. ${ }^{33}$ Lommel aber scheint es noch nicht darum gegangen zu sein, Jesu angeblich „arische" Abstammung nachzuweisen - erst im 20. Jahrhundert wird die Panthera-Tradition bei Emil Jung ${ }^{34}$ und (mit größerem Einfluss dann) Walter Grundmann und Emanuel Hirsch herangezogen, um Jesus zum „Arier“ zu machen. Vor allem Grundmann, der ab 1939 als wissenschaftlicher Leiter des „Instituts zur Erforschung und Beseitigung des jüdischen Einflusses auf das deutsche kirchliche Leben" (Eisenach) besonders einflussreich

\footnotetext{
${ }^{29}$ Zum Folgenden vgl. auch Fenske (2005:14-16 und 144-145).

${ }^{30}$ Weiterführend zu diesem Text vgl. Lona (2005:100-102).

${ }^{31}$ Hierzu weiterführend Klauck (2002:268-279).

${ }^{32}$ Hierzu z.B. Maier (1978:267; 314 n. 625).

${ }^{33}$ Lommel (1848:32). Lommels Buch war mir nicht zugänglich - ich übernehme deswegen die Angaben bei Fenske (2005:60).

${ }^{34}$ Vgl. Jung (1943 [1922]:56-58; 288-291; 1924). Eine knappe Einführung zu Jungs Denken gibt Fenske (2005:143-144).
} 
wurde ${ }^{35}$ sucht in seinem 1940 erschienenen „Jesus der Galiläer und das Judentum“ zunächst zu beweisen, dass Maria „eine galiläische Nichtjüdin“ gewesen sei (Grundmann (1940:196). Dann muss derselbe Prozess für die väterliche Linie Jesu durchgeführt werden. Dabei wird auf das angeblich hohe Alter der Panthera-Tradition (die doch offensichtlich die in Mt und Lk geäußerte Vorstellung der Jungfrauenschaft Mariens voraussetzt) verwiesen,$^{36}$ um dann gleichzeitig die Aussagen der Synoptiker als „apologetisch“ zu desavouieren. Interessanterweise aber werden selbst die Aussagen der Panthera-Tradition nicht ernst genommen, sondern aus dem Vater Jesu sein Großvater gemacht - eine stärkere Verdrehung der Quellenlage ist kaum denkbar. Grundmann (1940:198-9) schreibt:

Dieser Name [Panthera bzw. Panther; TN] ist aber ein völlig unjüdischer Name. Ihn soll einer, der zu Davids Geschlecht gehört ... getragen haben? Das ist unmöglich. Es bleibt keine andere Konsequenz: Der Name ist der eines Galiläers, der selbst im Zusammenhang mit der gewaltsamen Judaisierung einen zweiten Namen annahm oder erhielt und der seinen Kindern auch alttestamentliche Namen hab. Hatten wir schon mit großer Wahrscheinlichkeit für die Mutter Jesu ihre galiläische unjüdische Herkunft annehmen müssen, so werden wir auf Grund verschiedener Beobachtungen für den Vater in die gleiche Richtung gedrängt. ... In der christlichen Gemeinde hat sich das Wissen darum erhalten, die jüdische Tradition aber machte aus dem Sohn des Panthersohns selbst einen Panthersohn, und noch später wird aus diesem Panther ein Soldat, der die Maria verführt habe und ihr Jesus gezeugt habe.

Das Bild des arischen Jesus wurde dann gerne mit der Vorstellung verbunden werden, Jesus habe sich in tödlicher Auseinandersetzung mit dem Judentum befunden. So schreibt etwa Georg Bertram, ab 1943 Nachfolger Grundmanns als Leiter des „Instituts zur Erforschung und Beseitigung jüdischen Einflusses auf das deutsche kirchliche Leben,“ Jesus die Rettung des Abendlandes vor jüdischen Ansprüchen auf die Weltherrschaft zu:

\footnotetext{
${ }^{35}$ Offizieller Leiter war Siegfried Leffler. Grundmann fungierte als wissenschaftlicher Leiter als dessen Stellvertreter. Grundmann war bereits im Jahr 1930 der NSDAP beigetreten, wurde später sogar mit dem „Goldenen Parteiabzeichen" bedacht und war ab 1934 förderndes Mitglied der SS. 1933 wurde er zum Mitbegründer der sächsischen „Deutschen Christen“. Zu Grundmann vgl. u.a. Schenk (2002) und Osten-Sacken (2002a).

${ }^{36}$ Grundmann (1940:197) spricht, ohne klare Belege anzugeben, die Traditionen reichten „mindestens bis 80 n.Chr." zurück.
} 
Tatsächlich aber war seine [des Judentums; TN] Macht gebrochen, seit Jesus von Nazareth dem jüdischen Machtstreben die Axt an die Wurzel gelegt und damit das Abendland vor der Knechtung unter den jüdischen Mammonskult bewahrt hat. ... Die Botschaft Jesu von Nazareth hat das Abendland vor dem Judentum bewahrt.

(Bertram (1943:88-89)

Weitere Verbreitung als die genannten „wissenschaftlichen“ Werke aber erreichten einige an ein breites Publikum gerichtete Schriften diese gehen auf der gezeichneten Linie weiter - und sind in ihren Formulierungen manches Mal noch drastischer. So bezeichnet die 1935 gleichzeitig in Wien und Dresden erschienene „antisemitische Christenfibel“ (gewidmet Julius Streicher!), Christus kurz und bündig als den „schärfste[n] Antisemit[en] aller Zeiten“(Köber 1935:24). ${ }^{37}$ In hohen Auflagen wurden auch einige populäre Schriften des bereits mehrfach genannten Eisenacher „Instituts zur Erforschung und Beseitigung des jüdischen Einflusses auf das deutsche kirchliche Leben“ verbreitet. Hier entstand nicht nur „Die Botschaft Gottes“ (eine von Hinweisen auf die jüdischen Wurzeln Jesu und des Urchristentums befreite Version des Neuen Testaments), ein „entjudetes“ Gesangbuch (beide 1940), sondern auch der Katechismus „Deutsche mit Gott: Ein deutsches Glaubensbuch“ (1941), in dem u.a. zu lesen ist:

Jesus aus Nazareth in Galiläa erweist in seiner Botschaft und Haltung einen Geist, der dem Judentum in allen Stücken entgegengesetzt ist. Der Kampf zwischen inm und den Juden wurde so unerbittlich, daß er zu seinem Kreuzestod führte. So kann Jesus nicht Jude gewesen sein. Bis auf den heutigen Tag verfolgt das Judentum Jesus und alle, die inm folgen, mit unversöhnlichem $\mathrm{Haß}$. Hingegen fanden bei Jesus besonders arische Menschen Antwort auf ihre letzten und tiefsten Fragen. So wurde er auch der Heiland der Deutschen. ${ }^{38}$

Eine Kommentierung dieser Sätze - erschienen 1941 in Weimar und gedruckt in einer Auflage von mehr als 100.000 Exemplaren - erübrigt sich.

\footnotetext{
${ }^{37}$ Weiterführend hierzu Schenk (2002:226-7; dort ebenfalls zitiert), sowie v.a. Heer (1981:365-76).

${ }^{38}$ Grundmann (1941:46), zitiert nach Heschel (2002:78-9). Dort finden sich auch die entsprechenden Angaben zu den weiteren an ein breites Publikum gerichteten Veröffentlichungen des Instituts.
} 


\section{PAULUS}

Die bisher genannten Punkte konzentrierten sich v.a. auf die Darstellung Jesu von Nazaret bzw. die Exegese der Evangelien des Neuen Testaments und auf von daher motivierte Thesen zum Alten Testament. Demgegenüber rückt Paulus sicherlich in den Hintergrund. Trotzdem ist es interessant zu beobachten, welche Paulusexegesen sich bei antisemitischen Autoren des 19. und 20. Jahrhunderts beobachten lassen. Während wir heute den Juden Paulus als die vielleicht entscheidende historische Persönlichkeit sehen würden, die das Christentum für die „Nationen“ geöffnet hat und die so eine entscheidende Basis für seine weltweite Durchsetzung legte, neigten viele antisemitisch denkende Autoren dazu, ihn als „zu jüdisch“ abzulehnen. ${ }^{39}$ Ein Grundimpetus für die spätere negative Paulusrezeption in antisemitischen Kreisen mag von Johann Gottlieb Fichte ausgegangen sein, der Paulus für die „Ausartung des Christenthums“ (Fichte 1806:190) verantwortlich machte, da er Christentum und Judentum zu kombinieren suchte.

Spätere Autoren haben diese Linie vertieft und zum Teil mit ihrer Ablehnung des Alten Testaments in Verbindung gebracht. ${ }^{40}$ Paulus wird für die angebliche „Rejudaisierung“ des Christentums verantwortlich gemacht. So wirft etwa der Göttinger Orientalist Paul de Lagarde (1827-1891) Paulus vor, er sei Schuld daran, dass das Alte Testament in der Kirche angenommen worden sei, an „dessen Einflusse das Evangelium, soweit dies möglich, zugrunde gegangen ist“" (De Lagarde [1873] 1934:68). Dass auch die in Röm 9-11 geäußerte Israel-Theologie bei dieser Ablehnung des Paulus eine Rolle spielen konnte, zeigt etwa Alfred Rosenberg, der explizit Ausschnitte aus Röm 9 und 11 paraphrasiert, um zu zeigen, wie sehr Paulus „sich bewußt gewesen“ sei, „doch eine jüdische Sache zu vertreten“ (Rosenberg [1930] 1941:75).

Eine andere Gruppe von Autoren sieht Paulus in einem inneren Zwiespalt, der mit seinem jüdischen Hintergrund zu tun hat, den er auch als Christ nie ablegte. ${ }^{41}$ Typisch diese zwiespältige, insgesamt aber doch ablehnende Stellung gegenüber Paulus scheint mir ein 1943 von dem bereits erwähnten Gießener Neutestamentler Georg Bertram verfasster Aufsatz. Bertram (1943: 90) stellt hier die Frage, inwiefern Paulus „der einst von der

\footnotetext{
${ }^{39}$ Erneut können hier nur einige Linien gezogen werden. Weiterführend vgl. v.a. Bell (2005:355-64) [Lit!].

${ }^{40}$ So beendet Dinter (1922:330), sein Nachwort mit der Forderung das Alte Testament und Paulus aufzugeben, um zurück zu Christus zu gelangen.

${ }^{41}$ Auch heute würde man mit Fug und Recht behaupten, Paulus habe sich sein Leben lang als Jude gefühlt; dies aber hat nichts mit den rassenideologisch unterbauten Aussagen der genannten Autoren zu tun.
} 
jüdischen Zentralbehörde nach Damaskus entsandt wurde, in einem letzten geistesgeschichtlichen Sinne Judensendling auch als christlicher Apostel“ geblieben sei. Anders als Jesus wird Paulus als „seiner Herkunft nach echter Jude “42 bestimmt: Dieses Judentum habe Paulus, obwohl er wenigstens in wichtigen Linien Jesus verstanden habe, nie ganz ablegen können. Dies sucht Bertram mit Aussagen über die Stellung des Paulus zum Staat, ${ }^{43}$ seiner angeblichen Unterstützung des Jerusalemer Zentralismus, ${ }^{44}$ seinem angeblichen Synkretismus ${ }^{45}$ und anderen Punkten zu belegen. Das von Paulus verkündigte Christentum sei deswegen ,judaisiertes“ Christentum voller negativer Auswirkungen gewesen - allerdings habe man es in einer „verjudeten Welt“ (Bertram 1943: 136) auch nur als solches verstehen können. Von daher spricht Bertram Paulus durchaus eine gewisse geschichtliche Bedeutung zu, lehnt inn aber letztlich als „zu jüdisch“ ab, da das Christentum ja von allen jüdischen Einflüssen zu reinigen sei.

Mit dieser Einstellung scheint Bertram nicht allein gewesen zu sein. Susannah Heschel schreibt in einer Untersuchung über das Eisenacher „Institut zur Erforschung und Beseitigung des jüdischen Einflusses auf das deutsche kirchliche Leben“: ${ }^{46}$

\footnotetext{
${ }^{42}$ Bertram (1943:90). Wie sehr Bertrams Darstellung ideologisch bestimmt ist, zeigt sich auch darin, dass er eine bei Hieronymus zitierte Tradition anführt, auch die Familie des Paulus stamme aus Galiläa. Anders als Jesu Familie aber wird „man ... sie nicht zu den Nachfahren der alteingesessenen Galiläer zu rechnen haben, sondern zu den jüdischen Sendlingen des 1. vorchristlichen Jahrhunderts, die Galiläa jüdisch durchdringen sollten“ (1943:92).
}

${ }^{43}$ Bertram (1943:97): „Paulus ist mit dem allem Nutznießer des Römischen Reiches. Er wie alle Juden nehmen in allem an dem Leben und der Kultur des Römischen Reiches teil, ohne doch irgendeine sittliche oder staatsbürgerliche Verpflichtung zu empfinden oder anzuerkennen. Der Staat ist eine von Gott gesetzte Ordnungsmacht, ohne die die Menschen, jedenfalls die Juden sich untereinander auffressen würden. Das ist die Meinung der Rabbinen und das ist auch die des Paulus."

${ }^{44}$ Ohne es direkt aussprechen zu müssen, greift Bertram damit auch die katholische Kirche an: Paulus habe „eine Entwicklung vorbereitet, die im Gegensatz zu der dem Christentum eigentümlichen völkischen Prägung ... auf lange Zeit die Christenheit dem Anspruch Roms auslieferte. Auch hier hat sich der jüdische hierarchische Gedanke der zentralen Weltbeherrschung mit dem politischen Prinzip des Römischen Reiches verbunden und so dem Abendland eine weitgehende Zersetzung der einzelnen Volkstümer und die laufende Bekämpfung und Zurückdrängung ihrer Ansprüche durch den Zentralismus der hierarchischen Organisation gebracht."

\footnotetext{
${ }^{45}$ Besonders jüdisch sei Paulus gerade da in seiner „Grundsatzlosigkeit“: „Denn in dem Satz: den Juden ein Jude, den Griechen ein Grieche, allen alles werden, ist die Grundsatzlosigkeit zum Grundsatz erhoben. Die Freiheit vom Gesetz aber ist nicht nur nach der Theorie des Paulus, sondern auf Grund der Verkündigung und des Verhaltens Jesu tatsächlich die unaufgebbare Grundlage aller evangelischen Predigt. Eine Rücksicht auf Judaisten und ihre besonderen Hemmungen durfte es da nicht geben“(Bertram 1943:127).

${ }^{46}$ Heschel (2002:81-2). Im selben Beitrag berichtet Heschel (2002: 84-5) über die (allerdings gescheiterten) Vorschläge von Superintendent Hugo Pich für eine gründliche Dejudaisierung des Neuen Testaments - Titel „Der Jude Scha-ul und seine Christusverkündigung im Feuerschein des jüdischen Weltenbrandes“.
} 
Bei ihren Debatten darüber, wie man das Christentum ,entjuden“ könne, diskutierten die Institutsmitglieder auch darüber, wie ,Judentum' definiert werden solle. Eisenhuth ${ }^{47}$ meinte, daß das gesamte ,Alte Testament' einschließlich der prophetischen Bücher beseitigt werden müsse; das ,Neue Testament' aber sollte von allen Texten bis auf die vier Evangelien gereinigt werden - Paulus betrachtete er als jüdischen Theologen.

\section{NACHWIRKUNGEN}

Obwohl hier also im Zusammenhang mit zentralen Linien auch bereits einige besonders berühmte - berüchtigte - Namen zusammengestellt werden konnten, ist es wichtig zu betonen, dass es sich dabei weder um isolierte Einzelfälle handelt, noch dass zumindest die genannten Personen ihre Thesen aus Angst vor dem Regime verbreiteten ${ }^{48}$ - in vielen Fällen ist stattdessen von Überzeugungstätern auszugehen, von denen zumindest einige auch nach dem 2. Weltkrieg weiterhin beträchtlichen Einfluss ausübten. Die Konzentration auf das Phänomen „Exegese im Dritten Reich“ soll zudem keineswegs verschleiern, dass die antisemitischen Ideen, die die in den genannten Werken betriebene „Exegese“ unterbauen, ihre Wurzeln bereits in früherer Zeit finden. ${ }^{49}$

Wichtig aber ist auch, dass viele der genannten Autoren die Möglichkeit hatten, ihre Aussagen in Publikationen zu verbreiten, die auch nach 1945 weiter wirkten. Vor allem aber zeigt sich zumindest in manchen Fällen, dass sich Ideen mit antijüdischem oder antisemitischem Hintergrund verselbständigten und „wissenschaftliche Legenden“ entstanden, die als immer wieder wiederholte Stereotypen auch von wohlmeinenden Exegeten und Theologen bis in die jüngste Zeit hinein weiter vertreten wurden und werden.

Das konkreteste und bekannteste Beispiel, von dem (wohl bis heute) ein ungeheuerer Einfluss ausgeht, ist das berühmte „Theologische Wörterbuch zum Neuen Testament" (ThWNT) ${ }^{50}$ - ein bis heute regelmäßig

\footnotetext{
${ }^{47}$ Zu Eisenhuth wie auch den Umständen seiner Ernennung zum Professor vgl. Schenk (2002:185-190).

${ }^{48}$ Interessant ist, dass die Arbeit des Eisenacher Instituts durch die nationalsozialistische Regierung, der es an einer Assimilation des Christentums nicht gelegen war, im Grunde nicht anerkannt war. Über Versuche, der Institutsleitung, das Propagandaministerium von der Wichtigkeit des eigenen Unternehmens zu überzeugen, berichtet Head (2004:77-8).

${ }^{49}$ Besonders Fenske (2005) zeigt immer wieder beeindruckend auf, wie die Entwicklung von Gedanken antisemitischer Exegese sich darstellt.

${ }^{50}$ Zur Problematik antisemitischer Aussagen in Artikeln des ThWNT erschienen bereits mehrere Publikationen, von denen allerdings zumindest die ersten zu wenig rezipiert wurden: Vgl. Vos (1984); Johnson (1986). Die m.W. erste sich dem Thema widmende Untersuchung in einer wichtigen neutestamentlichen Fachzeitschrift stammt von Casey (1999).
} 
herangezogenes Hilfsmittel zu Fragen neutestamentlicher Exegese, dessen erster Band nicht nur 1933 erschien - im Jahr der „Machtergreifung“ Adolf Hitlers - sondern das von Gerhard Kittel, seit 1933 Mitglied der NSDAP, initiiert und bis zum Ende des Krieges geleitet wurde. ${ }^{51}$ Sicherlich sollte nicht zu schnell von Kittels Einstellung auf die all seiner Mitarbeiter geschlossen werden. Während neben Kittel mehrere Mitarbeiter des ThWNT dem genannten Eisenacher Institut (W. Grundmann, K.G. Kuhn, G. Bertram, H. Odeberg, C. Schneider, H. Preisker und G. Delling) z.T. in leitender Funktion verbunden waren, ${ }^{52}$ und andere wie Ethelbert Stauffer aktiv die Bewegung des „Deutschen Christentums“ unterstützten, distanzierten sich andere wie Rudolf Bultmann klar von nationalsozialistischer Ideologie (z.B. Vos 1984: 91). Der seit 1929 in Bonn lehrende Karl Ludwig Schmidt (1891-1956), im ersten Band immerhin noch mit vier Beträgen vertreten, schließlich wurde noch im Jahr 1933 von den Nationalsozialisten abgesetzt - er hatte im gleichen Jahr noch den öffentlichen Dialog mit Martin Buber gesucht. ${ }^{53}$ Doch nun zu schließen, dass die Artikel der zuerst genannten Autoren voll von plumpen Antisemitismen seien, während sich in den anderen Texten nichts finde, was nicht zumindest potentiell antijüdisch ausgelegt werden kann, wäre falsch. ${ }^{54}$ Tatsächlich findet sich zumindest in den Artikeln Kittels kein Beispiel grob antisemitischer Aussagen. Umso gefährlicher aber sind Passagen, deren

\footnotetext{
${ }^{51}$ Kittels Einstellung wie auch sein Verhalten in der Zeit des Nationalsozialismus sind sehr unterschiedlich beurteilt worden - das Problem besteht u.a. darin, dass sich im Werk Kittels sehr große Gegensätze finden. So hat derselbe Autor, der sich noch in seinem 1926 erschienenen Band Die Probleme des Spätjudentums und das Urchristentum für eine vorurteilsfreie Exegese jüdischer Quellen einsetzte, vor allem in seiner 1933 erstmals erschienenen Schrift „Die Judenfrage“ für den Kampf des Christentums gegen das Judentum eingesetzt, das seit Christi Kreuzigung als verflucht anzusehen sei. Ab 1936 wurde er als aktiver Mitarbeiter der Abteilung „Judenfrage“ des Reichsinstituts für Geschichte des Neuen Deutschlands, später auch für das von Goebbels geförderte Institut zum Studium der Judenfrage „Antijüdische Aktion“, tätig. Vgl. hierzu auch Schenk (2002:198-9). Zudem war er ab 1939 dem von W. Grundmann geleiteten „Institut zur Erforschung des jüdischen Einflusses auf das deutsche kirchliche Leben" in Eisenach verbunden. So muss Kittel trotz einiger Aussagen, in denen er sich von den radikalsten antisemitischen Aussagen der NSDAP distanzierte, doch als von nationalsozialistischem Antisemitismus beeinflusst angesehen werden. Zur Diskussion um Kittel vgl. v.a. die Arbeiten von Siegele-Wenschkewitz (1978; 1980;1982). Darüber hinaus vgl. auch Ericksen (1977; 1983) sowie Rese (1979).

${ }^{52}$ Zur Geschichte des „Instituts zur Erforschung und Beseitigung des jüdischen Einflusses auf das deutsche kirchliche Leben“ vgl. u.a. Heschel (2002) sowie Osten-Sacken (2002b).

${ }^{53}$ Zu Schmidt vgl. Schwankl (1995), sowie Johnson (1986: 20-3), der Schmidt als „one of the most outspoken opponents of Nazi policies" (20) bezeichnet.

${ }^{54}$ So schreibt etwa Vos (1984:93): „Für das ThW schrieb Kittel insgesamt 26 Artikel. Sämtliche Beiträge sind Ausdruck des von Kittel 1926 formulierten Bestrebens, die jüdischen Texte ohne Vorurteile zu lesen. Von Antisemitismus findet man in diesen Artikeln keine Spur."

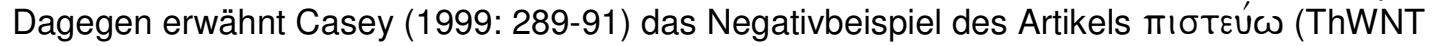
$\mathrm{VI}$ ) von Rudolf Bultmann (1959!) - Bultmann aber ist dafür bekannt, Mitglied der „Bekennenden Kirche“ gewesen zu sein, sich gegen den Arierparagraphen ausgesprochen und die Barmener Erklärung unterzeichnet zu haben.
} 
antijüdische Argumentationsbasis nicht immer auf den ersten Blick erkennbar ist: ${ }^{55}$

So endet etwa der von Kittel selbst verfasste Beitrag $\alpha \beta \beta \alpha^{\prime}$ mit den folgenden Sätzen: ${ }^{56}$ „In jedem Fall ... steht fest, daß der Gebrauch des Wortes [ $\alpha \beta \beta \alpha$; TN] in der Gemeinde Anknüpfung an die Gottesbezeichnung Jesu und damit bewußte Aneignung des von ihm verkündigten und gelebten Gottesverhältnisses ist. Der jüdische Sprachgebrauch zeigt, wie das urchristliche Vater-Kindes-Verhältnis zu Gott alle im Judentum gesetzten Möglichkeiten an Intimität weit übertrifft, vielmehr an deren Stelle etwas Neues setzt." Auf Kittels Aussagen nimmt im 3. Band der von Ethelbert Stauffer verantwortete Abschnitt „Die urchristliche Gottestatsache und ihre Auseinandersetzung mit dem Gottesbegriff des Judentums“ im Artikel $\theta \varepsilon o ́ s$ ktl. (Stauffer 1938:91-3). Stauffer schreibt hier, nachdem er die Scheu des Judentums, den Gottesnamen auszusprechen, beschrieben hat: „Jesus braucht den Ausdruck $\theta \varepsilon o ́ s$ in aller Unbefangenheit .... Am häufigsten begegnet raтńp, die eigentliche Gottesbezeichnung in Jesu Munde, charakteristisch für die einzigartige Gottesbotschaft Jesu, die das AT und vollends die Apokalyptik weit hinter sich läßt“ (Stauffer 1938:92). Noch einen Schritt weiter geht Walter Grundmann in seiner 1938 erschienenen Monographie „Die Gotteskindschaft in der Geschichte Jesu“, wo er der Frage ein ganzes Kapitel widmet (1938:65-78). ${ }^{57}$ Hier schreibt er etwa, dass die „Beobachtung“ Johannes Leipoldts, dass selbst „in den rabbinischen Bildreden, die von Gott dem Vater reden“ „ein harter Zug“ zu erkennen sei, mit der jüdischen Gottesvorstellung zusammenhänge: „wo Gott und Welt, Gott und Menschen getrennt sind und Gott vorwiegend als Herr und Richter gesehen wird, kann keine auch das Gefühl innerlich ergreifende und wandelnde Gottesbezeichnung entstehen, sondern muß das Harte und Pflichtmäßige in den Vordergrund treten.“58

\footnotetext{
${ }^{55}$ Ein gutes Beispiel gibt über das im Folgenden Gesagte hinaus etwa Casey (1999:282-6),

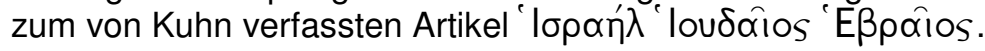

${ }^{56}$ Kittel (1933 5-6); zitiert auch bei Vos (1984:93). Interessant in diesem Zusammenhang ist auch der auf der gleichen Linie liegende von Stauffer verantwortete Abschnitt (1938: 91-3).

${ }^{57}$ Grundmann (1938a). Im Vorwort (1938a:9) bezeichnet der Verfasser sich selbst als „dem Ansatz der neuen Geschichtsforschung im rassenseelischen Denken verpflichtet“. Zum Thema vgl auch Grundmanns kurze Auslassungen in seinem Artikel kpó' $\omega$ (1938:902).

${ }^{58}$ Grundmann (1938a:66). Der von Grundmann hier zitierte Johannes Leipoldt (1880-1965) war ab 1909 Professor für Neues Testament in Kiel und einer der Lehrer Grundmanns. Wie sehr auch er antijüdisch eingestellt war, zeigt sich in seinem für RAC 1 verfassten Beitrag „Antisemitismus“ (erschienen 1950, erstellt aber bereits 1944). Vergleichbare, etwas vorsichtiger formulierte Abschnitte finden sich aber auch in dem nach 1945 verfassten „Die Geschichte Jesu Christi“. Vgl. Grundmann (1956:65-67).
} 
Was hier nur in wenigen Sätzen formuliert ist, machte lange Zeit auch in Kreisen, denen man keineswegs Antijudaismus vorwerfen kann, wissenschaftlich „Karriere.“ Nach dem Krieg hat vor allem Joachim Jeremias die These populär gemacht, dass das aramäische Wort Abba stehe für die kindliche Anrede seines Vaters stehe. ${ }^{59}$ Eine solche Anrede Gottes aber sei im Judentum der Zeit Jesu undenkbar gewesen. In dieser Gottesanrede zeige sich der fundamentale Unterschied zwischen der Gottesbeziehung Jesu von Nazaret und der seiner Zeitgenossen: Jeremias (1971:73) spricht in diesem Zusammenhang vom „Herzstück des Gottesverhältnisses Jesu“60 und schreibt (1966: 63): ,[E]s wäre für jüdisches Empfinden unehrerbietig und darum undenkbar gewesen, Gott mit diesem familiären Wort anzureden. Es war etwas Neues und Unerhörtes, daß Jesus es gewagt hat, diesen Schritt zu vollziehen. Er hat so mit Gott geredet, wie das Kind mit seinem Vater, so schlicht, so innig, so geborgen."

Eine Vielzahl weiterer Beispiele, die auf ganz unterschiedlichen Ebenen - von der unbewussten Übernahme von Stereotypen über ein „Spätjudentum" bis hin zu klar antisemitisch motivierten Fehlurteilen - lässt sich aufzeigen: Besonders extreme Beispiele finden sich vor allem in den Beiträgen der bereits genannten Walter Grundmann ${ }^{61}$ und Georg Bertram. ${ }^{62}$ Der Artikel kớkos im 3. Band geht auf Grundmann zurück, ${ }^{63}$ die entsprechenden Passagen zur LXX aber sind von Bertram überarbeitet: In dem mit "Tò kákov als ethischer Begriff" betitelten Abschnitt finden sich die klassischen antisemitischen Stereotypen über das „späte Judentum“. So heißt es etwa:

Was im Prophetismus eine lebendige Deutungskategorie der Geschichte war, hervorgebrochen aus dem lebendigen Gottesglauben, ist hier [in der späteren Weisheitsliteratur; TN] zum Schema erstarrt und verfälscht, in das alles hineingepreßt wird" und etwas später: „So oberflächlich und schematisch wie bei dem Übersetzer der Prv [= Spr LXX] ist das sittliche Urteil des Judentums jener Zeit überhaupt. ... Damit ist die Verkrampfung der

\footnotetext{
59 Jeremias (1966:63-64) verwahrt sich allerdings gegen die Annahme, dass hier einfach das Lallwort des Kleinkindes übernommen worden sei.

${ }^{60}$ Siehe auch auf der gleichen Seite: „In der Gottesanrede 'Abba äußert sich das letzte Geheimnis der Sendung Jesu. Er wußte sich bevollmächtigt, Gottes Offenbarung zu vermitteln, weil Gott sich inm als Vater zu erkennen gegeben hatte (Mt 11,27 par)."

${ }^{61}$ Vgl. hierzu z.B. Casey (1999:286-289) zu Grundmann (1938c).

${ }^{62}$ Zu Bertram vgl. u.a. Heschel (2002: 84-87).

${ }^{63}$ Vgl. Grundmann (1938d). Die im Folgenden zitierten Passagen finden sich auf 1938:479 und 480. Die Passage wird auch erwähnt bei Vos (1984:97-98).
} 
sittlich-religiösen Haltung vollendet, die für die Gesetzesfrömmigkeit des Judentums bezeichnend ist.

Ähnlich formulierte Gedanken finden sich in Rudolf Meyers Artikel k $\alpha$ $\theta$ pós $\kappa \tau \lambda$ ebenfalls im dritten Band: ${ }^{64}$ Nachdem der Autor der „alttestamentlichen Religion“ „Reste primitiven Denkens“ im Bezug auf Fragen der Reinheit und Unreinheit bescheinigt (S. 419) und die Propheten in ihrer Forderung nach ethischer Reinheit als "Wegbereiter für die Religion Jesu“ (S. 420) bezeichnet hat, fährt er fort:

Es wurde der Mangel der spätjüdischen offiziellen Religion, daß sie der Forderung kultischer Reinheit ein weit übertriebenes Übergewicht gegenüber den innersten Anliegen der Religion einräumte und daß sie unfähig zur Abstoßung des Primitiven blieb. Beides führte $z u$ einer verhängnisvollen Verzerrung und Versteinerung der jüdischen Religion Meyer 1938:420.

Während der ideologische Hintergrund der Schreiber in den genannten Beispielen zu höchst verzerrenden Pauschalaussagen führt, finden sich auch Beispiele, in denen neutestamentliche Texte krass fehlinterpretiert werden, um sie antisemitischen Exegesen dienstbar zu machen. Immer wieder wird in diesem Zusammenhang Carl Schneiders Artikel zu $\mu \dot{\tau} \tau \omega \pi$ Tा im 4. Band erwähnt. In seiner Interpretation von Offb 13,16; 14,9 und 20,4 schreibt dieser:

Beim Zeichen des Tieres ist an allen drei Stellen deutlich auf die Tephillin angespielt, da hier Stirn und Hand genannt werden. Aus dieser Gleichsetzung wird die antijüdische Haltung der Apokalypse erkannt; Apk 13,16 bedeutet dann: Wer die Tephillin nicht trägt, wird von den Juden wirtschaftlich boykottiert. Eine der treibenden Mächte der Christenverfolgungen war ja noch zur Zeit der Apokalypse im römischen Reich das seit Nero am römischen Hof besonders einflußreiche Weltjudentum. ${ }^{65}$

Auf das Problem, dass Tephillin am linken Arm getragen werden, während die Offenbarung aber von der rechten Hand spricht, wird dann zwar in Fußnote 5 mit einem kurzen Hinweis auf die unklare Quellenlage eingegangen - die Aussagen über den Einfluss des „Weltjudentums“ - man beachte den

\footnotetext{
${ }^{64}$ Vgl. Meyer (1938). Meyer war zur Zeit der Drucklegung Assistent in Leipzig; über seinen weiteren Weg konnte ich keine Informationen erhalten.

${ }^{65}$ Vgl. Schneider (1942:639); angeführt auch bei Vos (1984:100-101).
} 
Ausdruck! - selbst auf Nero werden nur mit einem kurzen Literaturhinweis belegt.

An vielen weiteren Aussagen des Theologischen Wörterbuch zum Neuen Testament und seiner Rezeption ließe sich das Weiterwirken antisemitisch motivierter Exegese zeigen - doch auch dies ist keineswegs ein Einzelfall: Nicht nur Grundmann hat nach dem 2. Weltkrieg noch eine Reihe von Büchern - u.a. Kommentare zu den Synoptikern und Werke zur Rückfrage nach dem historischen Jesus - publiziert, die weiten Absatz fanden; ${ }^{66}$ auch andere Autoren blieben tätig: Ethelbert Stauffer (1902-1979) war zwar nicht Mitglied der NSDAP, sympathisierte aber lange Zeit mit den „Deutschen Christen“ und trat schon 1933 mit einem Beitrag mit dem Titel „Unser Glaube und unsere Geschichte: Zur Begegnung zwischen Kreuz und Hakenkreuz“67 hervor. Stauffers Position in der Zeit des „Dritten Reichs“ ist sicherlich deutlich ambivalenter als die Grundmanns oder Bertrams; immerhin wurde er nach einem Vortrag über „Augustus und Kleopatra“ aufgrund antifaschistischer Aussagen im Januar 1943 als Prodekan der Bonner Fakultät abgesetzt. Inwieweit sein Denken aber auch nach dem Zweiten Weltkrieg noch von Stereotypen antisemitischer Exegese beeinflusst war, zeigt exemplarisch ein noch 1982 in dem renommierten Standardwerk Aufstieg und Niedergang der römischen Welt erschienener, mehr als 100 Seiten langer Grundlagenartikel zu Jesus von Nazaret (Stauffer 1982). Hier wiederholt Stauffer in unglaublich direkter Weise eine ganze Palette von Stereotypen antisemitisch motivierter Exegese:

- Hauptkriterium der Rückfrage nach dem historischen Jesus ist für Stauffer das von inm so genannte "Skandalonkriterium,“ eine Abwandlung des Käsemannschen Kriteriums der Dissimilarität. Dabei entstehe das Bild Jesu als „eines Nonkonformisten, ..., eines Provokateurs. Dieses Bild hat den Vorzug, daß es uns zwei historische Tatsachen verständlich macht: einmal den tödlichen Jesushaß des zeitgenössischen

\footnotetext{
${ }^{66}$ Nach 1945 hat Grundmann noch die Kommentare zu den Synoptikern in der Reihe Theologischer Handkommentar zum Neuen Testament versorgt. Daneben erschienen u.a. zwei Jesusbücher (Grundmann 1956; 1975). Diese Schriften wurden aufgrund ihres geringen Preises, aber auch, weil sie in DDR-Zeiten nahezu die einzigen erhältlichen Arbeiten zum Thema darstellten, weit verbreitet und stehen bis heute nicht nur in so mancher Pfarrbibliothek, sondern sind auch aus den Handapparaten der Universitätsbibliotheken beileibe noch nicht verschwunden. Interessant ist Grundmanns Biographie in dem 1975 erschienenen Jesusbuch. Von Grundmanns Tätigkeit am Eisenacher Institut ist hier nicht die Rede, wohl aber von seinem Kriegseinsatz 1943-45, seinen Tätigkeiten und Ehrungen nach dem Krieg und seiner angeblichen Mitgliedschaft in der Studiorum Novi Testamenti Societas (SNTS).

${ }^{67}$ Stauffer (1933). Weiterführend zu Stauffer Wesseling (1995), dessen Aussagen allerdings sehr zurückhaltend sind.
} 
Judentums (der zur Kreuzigung Jesu geführt hat), zum anderen die vermittlungstheologischen Bemühungen der Urkirche (die sich in den Evangelien manifestieren)" (Stauffer (1982:9) Jesus wird so also so weit wie möglich von seiner jüdischen Umwelt gelöst. Stauffer spricht im unmittelbaren Kontext nur von „etwaigen [Herv. TN] Gemeinsamkeiten zwischen Jesus und dem Spätjudentum." Dieses wird Jesus als ein feindseliger Block entgegengestellt, der schließlich auch seinen Tod verschuldet.

- $\quad$ Dieses Negativbild des Judentums der Zeit Jesu zeichnet Stauffer in grellen Farben aus. So begegnen in seinem Beitrag nicht nur auf Schritt und Tritt die üblichen Vorurteile über Pharisäer als Heuchler, „Superfromme“, deren Seelsorge als "Gesinnungsterror" bezeichnet wird. Stauffer schreckt auch nicht davor zurück zu schreiben, die Pharisäer seien „Gott und den Menschen ein Greuel“ (Stauffer 1982:55). Vor allem aber zeichnet er das Bild eines von verblendeten Torafanatikern unterdrückten Judentums, dessen Führer ein Überwachungs- und Bespitzelungssystem aufgebaut hätten, das die Wirklichkeit totalitärer Staaten des 20. Jahrhunderts heraufbeschwört, aber kaum etwas mit den tatsächlichen Möglichkeiten und Gegebenheiten der Zeit Jesu zu tun hat. ${ }^{68}$

- $\quad$ Auch in seinen Aussagen zum Alten Testament schließt Stauffer an Linien an, die wir bereits verfolgen konnten. Jesus von Nazaret habe die Tora in schärfster Weise kritisiert und abgelehnt. Dies hindert Stauffer aber nicht daran, zumindest prophetische Texte, aber auch Psalmen positiv zu zitieren.

Bei der Lektüre stellt sich fortwährend die Frage, wie es dazu kommen konnte, dass das Herausgebergremium eines internationalen Standardwerks einen solchen Beitrag zum Druck freigeben konnte.

\section{FAZIT - ASPEKTE DER HEUTIGEN SITUATION}

Die heutige Situation zu überblicken und angemessen zu beurteilen ist - vor allem in wenigen Sätzen - kaum möglich. So fehlt in vielerlei Hinsicht das notwendige Datenmaterial, um wirklich wissenschaftlich fundierte Aussagen machen zu können. Allerdings ist es auch verständlich, warum genauere Daten nicht vorliegen, handelt es sich doch um ein allzu heißes Eisen, an dem

\footnotetext{
${ }^{68}$ Vgl. besonders die Ausführungen in dem Abschnitt, der den Titel „Der Polizeiapparat“ trägt: Vgl Stauffer (1982:98-102). Interessant ist hier der Umgang mit den Quellen: So werden hier auf Schritt und Tritt rabbinische Quellen herangezogen, ohne zu fragen, ob diese für die Zeit Jesu aussagekräftig sind, inwiefern sie als repräsentativ gelten können oder was sie wirklich aussagen wollen.
} 


\section{Vom Umgang mit biblischen Texten in antisemitischen Kontexten}

man sich leicht verbrennen könnte. Vor allem aber muss zwischen der Situation in der wissenschaftlichen Fachdiskussion und dem, was davon in den Kirchenleitungen, den Gemeinden, aber auch im gesellschaftlichen Diskurs ankommt, differenziert werden. Die Frage der Breitenwirkung einer Aufklärung gegen antijüdische wie antisemitische Stereotypen in wissenschaftlicher Theologie lässt sich m.E. nur ansatzweise und anhand einiger Schlaglichter beantworten. So verstehen sich die folgenden Ausführungen in erster Linie als Beispiele für Veränderungen, die sich in den vergangenen Jahrzehnten beobachten ließen, als Zeichen von Trends, deren Breitenwirkung aber nicht immer abzuschätzen ist.

Zumindest in wissenschaftlichen Kreisen weitgehend überwunden erscheint inzwischen immerhin die oben kurz skizzierte Vorstellung eines „Spätjudentums“, mit der einher meist ein Desinteresse bzw. eine klare Abwertung jüdischer Literaturen der hellenistisch-römischen Zeit ging. Im deutschsprachigen Raum hat vor allem Karlheinz Müller konsequent mit vielen damit verbundenen Theorien aufgeräumt, ${ }^{69}$ die es auch nach 1945 leicht machten, Jesus von Nazaret als eine Art von unverstandenem Genie zu beschreiben, das nicht konsequent als ,jüdischer Mensch“, sondern vor dem Hintergrund und in Abgrenzung zum Judentum seiner Zeit zu sehen sei. Die erfreulichen Zeichen einer Bewegung in deutlich ausgewogenere Richtungen sind klar ersichtlich: So wächst nicht nur das Interesse an den (aus katholischer Sicht) deuterokanonischen, aus evangelischer Perspektive apokryphen Schriften des Alten Testaments, mehr und mehr rücken ,jüdische Pseudepigraphen“ ins Zentrum des Interesses der Forschung. Kaum eine wissenschaftliche Publikation spricht heute noch vom „Spätjudentum“ - mit hoher Sensibilität gerade auf die Implikationen der Begriffswahl werden vielmehr Begriffe wie „Frühjudentum“ oder „mittleres Judentum,“ „Judentum des Zweiten Tempels“ oder „Judentum der hellenistisch-römischen Zeit“ diskutiert. Aus vergleichbaren Gründen ist auch der Begriff der „zwischentestamentarischen Epoche“ etwas in Misskredit gelangt - setzt er doch einen (etwa mit der späten persischen Zeit einsetzenden und mit Jesus von Nazaret endenden) zeitlichen Bruch zwischen den Texten des Alten und denen des Neuen Testaments (und damit indirekt einen Bruch göttlichen Offenbarungshandelns am Judentum) voraus, der gerne mit der Vorstellung eines „Spätjudentums“ in Verbindung gebracht wurde.

Trotzdem: Die sogar noch weitergehende Tendenz, Neues Testament und Altes Testament voneinander abzugrenzen und dabei das Alte Testament als die Schrift eines dunklen, zornigen, kaum verstehbaren grausamen Gottes

\footnotetext{
${ }^{69}$ Entscheidend hierzu Müller (1983:103-117). Entscheidende ideologische Linien hinter der Theorie des „Spätjudentums“ hat bereits G.F. Moore (1921) aufgedeckt.
} 
von einem hell leuchtenden Bild eines befreienden Neuen Testaments abzugrenzen, lässt sich - wenn auch kaum mehr in wissenschaftlichen Publikationen - so doch im allgemeinen Bewusstsein weiterhin beobachten: Ein Indiz im deutschsprachigen Raum zeigt sich v.a. darin, dass alttestamentliche Lesungstexte in Gottesdiensten gerne einmal weggelassen werden und man kaum einmal eine Predigt zu hören bekommt, die sich auf einen alttestamentlichen Text bezieht. Dass dabei auch das Neue Testament seiner historischen wie literarischen Wurzeln beraubt wird, wird dabei meist nicht erkannt.

Zumindest im wissenschaftlichen Diskurs ist sicherlich auch das von Ernst Käsemann entwickelte Kriterium der „Dissimilarität“ weitgehend überwunden, das den Kern dessen, was wir über den historischen Jesus wissen können, ausgerechnet da suchte, wo Aussagen über Jesus weder aus seinem jüdischen Hintergrund, noch aus Entwicklungen der (noch zu sehr jüdisch geprägten) frühesten Gemeinden erklärt werden können. Dies heißt aber nicht, dass nicht auch unter einigen Autoren der so genannten „Third Quest ${ }^{40}$ wieder Tendenzen zu beobachten sind, einen historischen Jesus zu zeichnen, der nur sehr wenig mit dem palästinischen Judentum seiner Zeit zu tun hat. ${ }^{71}$

Trotz dieser Beobachtungen, von denen zumindest einige einen Trend markieren, der sich auch bis hinein in kirchenamtliche Dokumente beobachten lässt, bleibt das Verhältnis zwischen Antisemitismus und Exegese weitgehend unaufgearbeitet. Die Frage nach antisemitischer Exegese, ihren ideologischen Hintergründen und ihren direkten wie indirekten Auswirkungen bleibt somit aktuell - das Problem ist somit keineswegs ein bloßes Problem der Vergangenheit, sondern im wahrsten Sinne des Wortes ein „historisches Problem", Problem also einer Vergangenheit, die uns heute angeht - und somit bleibende Herausforderung nicht nur für Historiker, Exegeten und Theologen, sondern für Kirchen und Gesellschaft. ${ }^{72}$

\footnotetext{
${ }^{70}$ Interessant ist die Bezeichnung „Third Quest“: Ihr liegen Rekonstruktionen der Forschungsgeschichte zugrunde, in denen die Jahre des Nationalsozialismus mit ihren Versuchen, einen „arischen“ Jesus zu rekonstruieren, nicht berücksichtigen. Ob dieser Weg, (gefährlichen) Aspekten der Forschungsgeschichte aus dem Weg zu gehen, sinnvoll ist, kann bezweifelt werden. Zum Problem vgl. auch Head (2004:57-59).

${ }^{71}$ Vor allem Autoren des von R. Funk initiierten „Jesus Seminars“ wurde - ohne dass es sich dabei um Antisemiten handeln würde - vorgeworfen, der von innen rekonstruierte Jesus habe nur sehr wenig mit dem palästinischen Judentum seiner Zeit zu tun. Vgl. etwa die Kritik von Pearson (1995). Zur auch heute noch anhaltenden Diskussion um das Judentum in Galiläa vgl. z.B. Freyne (1997).

${ }^{72}$ Eine englische Version dieses Beitrags findet sich in E. Mason et al (Hrsg.), Oxford Handbook for the Reception of the Bible, Oxford et al. 2009.
} 


\section{Bibliographie}

Bärsch, C E 1988. Antijudaismus, Apokalyptik und Satanologie. Die religiösen Elemente des nationalsozialistischen Antisemitismus. ZRGG 40, 112-133.

Bell, R H 2005. The irrevocable call of God: An inquiry into Paul's theology of Israel. Tübingen: Mohr Siebeck. (WUNT 184.)

Bergen, D 1996. Twisted cross: The German Christian Movement in the Third Reich. Chapel Hill, NC: University of North Carolina Press.

Bertram, G 1940. Philo und die jüdische Propaganda in der antiken Welt, in Grundmann, W (Hrsg), in Christentum und Judentum: Studien zur Erforschung ihres gegenseitigen Verhältnisses, 79-105. Leipzig: Verlag Georg Wigand.

Bertram, G 1943. Paulus, Judensendling und Christusapostel, in Grundmann W (Hrsg), Germanentum, Christentum und Judentum: Studien zur Erforschung ihres gegenseitigen Verhältnisses, 83-136. Leipzig: Verlag Georg Wigand.

Bieringer, R, Pollefeyt, D, Vandecasteele-Vanneuville (eds), 2001. Anti-Judaism and the Fourth Gospel. Louisville, KY: Westminster John Knox.

Casey, M 1999. Some anti-semitic assumptions in the Theological Dictionary of the New Testament. NovT 41, 280-291.

Delitzsch, F 1924. Die große Täuschung. 2. Ausgabe. Loreb. Lorch (Württ): Karl Rohm Verlag.

Dinter, A 1922. Die Sünde wider die Liebe. Leipzig \& Hartenstein im Erzgebirge: Matthes \& Tost.

Ericksen, R P 1977. Theologian in the Third Reich: The case of Gerhard Kittel. Journal of Contemporary History 12, 595-622.

Ericksen, R P 1983. Zur Auseinandersetzung mit und um Gerhard Kittels Antisemitismus. EvTh 43, 250-270.

Fenske, W 1999. Und noch ein Jesus! Jesusbücher unter die Lupe genommen. Münster: Lit.

Fenske, W 2005. Wie Jesus zum "Arier" wurde: Auswirkungen der Entjudaisierung Christi im 19. und zu Beginn des 20. Jahrhunderts. Darmstadt: WBG.

Fichte, J G 1806. Die Grundzüge des gegenwärtigen Zeitalters: Dargestellt in Vorlesungen gehalten zu Berlin im Jahre 1804-1805. Berlin:

Realschulbuchhandlung.

Freyne, S 1997. Galilean questions to Crossan's Mediterranean Jesus, in Arnal, W E \& Desjardins, M (eds). Whose historical Jesus?, 63-91. Waterloo, Ont: Wilfrid Laurier University Press. (Studies in Christianity and Judaism 7.)

Friedländer, S 1998. Das Dritte Reich und die Juden: Die Jahre der Verfolgung 19331939. München: Beck.

Greive, H 1988. Geschichte des modernen Antisemitismus in Deutschland. 2. Ausgabe. Darmstadt: WBG.

Grundmann, W 1938a. Die Gotteskindschaft in der Geschichte Jesu und ihre religionsgeschichtlichen Voraussetzungen. Weimar: Verlag Deutsche Christen. (Studien zu deutscher Theologie und Frömmigkeit 1.)

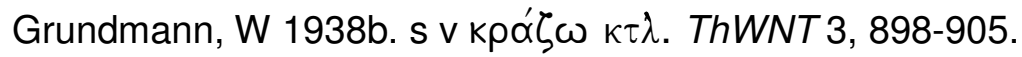

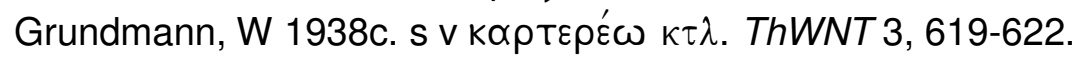

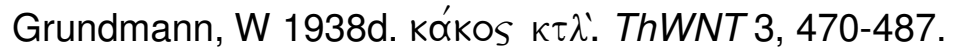

Grundmann, W 1940. Jesus der Galiläer und das Judentum. Leipzig: Wigand. 
Grundmann, W 1941. Deutsche mit Gott: Ein deutsches Glaubensbuch. Weimar: Verlag Deutsche Christen.

Grundmann, W 1956. Die Geschichte Jesu Christi. Berlin: Evangelische Verlagsanstalt.

Grundmann, W 1975. Jesus von Nazareth: Bürge zwischen Gott und Menschen. Göttingen: Musterschmidt.

Harnack, A von 1924. Marcion: Das Evangelium vom fremden Gott. 2. Ausgabe. Leipzig: Hinrich.

Head, P M 2004. The Nazi quest for an Aryan Jesus. Journal for the Study of the Historical Jesus 2, 55-89.

Heer, F 1981. Gottes erste Liebe: Die Juden im Spannungsfeld der Geschichte. München: Herbig.

Heschel, S 2002. Deutsche Theologen für Hitler: Walter Grundmann und das Eisenacher Institut zur Erforschung und Beseitigung des jüdischen Einflusses auf das deutsche kirchliche Leben, in Osten-Sacken, P von der (Hrsg), Das missbrauchte Evangelium: Studien zu Theologie und Praxis der Thüringer Deutschen Christen. Berlin: Institut Kirche und Judentum 70-90. (Studien zu Kirche und Israel 20.)

Hirsch, E 1939. Das Wesen des Christentums. Weimar: Verlag Deutsche Christen.

Hirsch, E 1989. Christliche Rechenschaft I, hrsg. von H. Hirsch. Tübingen: Katzmann.

Jeremias, J 1966. Abba: Studien zur neutestamentlichen Theologie und Zeitgeschichte. Göttingen: Vandenhoeck \& Ruprecht.

Jeremias, J 1971. Neutestamentliche Theologie, Erster Teil: Die Verkündigung Jesu. Gütersloh: Gütersloher Verlagshaus.

Johnson, M D 1986. Power politics and New Testament scholarship in the Nationalist Socialist Period. Journal of Ecumenical Studies 23, 1-24.

Jung, E [1922] 1943. Die Herkunft Jesu: Im Lichte freier Forschung. 6. Ausgabe. Wien: Wingolf.

Jung, E 1924. Die geschichtliche Persönlichkeit Jesu. Innsbruck: Universitäts-Verlag Wagner.

Kampling, R (Hrsg) 1999. „Nun steht dieses Sache aber im Evangelium ..." Zur Frage nach den Anfängen des christlichen Antijudaismus. Paderborn: Schöningh.

Kittel, G 1926. Die Probleme des palästinischen Spätjudentums und das Urchristentum. Stuttgart: Kohlhammer. (BWANT 36.)

Kittel, G 1929. Die Geschichte des Volkes Israel 3: Die Zeit der Wegführung nach Babel und die Aufrichtung der neuen Gemeinde. Stuttgart: Kohlhammer.

Kittel, G 1933. s v $\alpha \beta \beta \alpha$.' ThWNT 1, 4-6.

Klauck, H-J 2002. Apokryphe Evangelien: Eine Einführung. Stuttgart: Katholisches Bibelwerk.

Köber, R (Hrsg) 1935. Antisemitismus der Welt in Wort und Bild. Dresden: Groh.

Kraus, W 1997. Christologie ohne Antijudaismus? Ein Überblick über die Diskussion, in Kraus, W (Hrsg.), Christen und Juden: Perspektiven einer Annäherung, 2148. Gütersloh: Kaiser.

Kusche, U 1991. Die unterlegene Religion: Das Judentum im Urteil deutscher Alttestamentler: Zur Kritik theologischer Geschichtsschreibung. Berlin: Institut Kirche und Judentum. (Studien zu Kirche und Israel 12.)

De Lagarde, P 1934 (1886). Die Religion der Zukunft, in De Lagarde, P, Deutsche Schriften 1, 279-318. München: Lehmanns. 
De Lagarde, P 1934 (1873). Über das Verhältnis des deutschen Staates zu Theologie, Kirche und Religion: Ein Versuch, Nicht-Theologen zu orientieren, in De Lagarde, P, Deutsche Schriften 1, 45-90 München: Lehmanns.

Lommel, G 1848. Jesus von Nazareth. 2. Ausgabe. Offenbach.

Lona, H E 2005. Die „wahre Lehre“ des Kelsos. Übersetzt und erklärt, in Brox, N, Niederwimmer, K, Lana, H E, Prostmeier, F R, Ulrich, J, Kommentar zu frühchristlicher Apologeten. Freiburg: Herder. (KfA Ergänzungsband 1.)

Maier, J 1978. Jesus von Nazareth in der talmudischen Überlieferung. Darmstadt: WBG. (EdF 82.)

Meier, K 2001². Kreuz und Hakenkreuz: Die evangelische Kirche im Dritten Reich. München: Deutsche Taschenbuch.

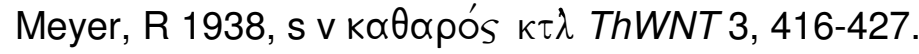

Moore, G F 1921. Christian writers on Judaism, HTR 14, 197-254.

Müller, K 1983. Das Judentum in der religionsgeschichtlichen Arbeit am Neuen Testament: Eine kritische Rückschau auf die Entwicklung einer Methodik bis zu den Qumranfunden. Frankfurt a m \& Berne: Peter Lang. (Judentum und Umwelt 6.)

Müller, K 1991. Die frühjüdische Apokalyptik, pages 35-173 in Müller, K, Studien zur frühjüdischen Apokalyptik. Stuttgart: KBW. (SBB 11.)

Nicklas, T 2006. Niet u draagt de wortel, maar de wortel draagt u (Rom 11, 18): Het Nieuwe Testament, bijbelse theologie en anti-judaisme. Nijmegen: Thieme.

Nicolaisen, C 1966. Die Auseinandersetzungen um das Alte Testament im Kirchenkampf 1933-1945. Diss. Hamburg.

Osten-Sacken, P von der 2002a. Walter Grundmann - Nationalsozialist, Kirchenmann und Theologe: Mit einem Ausblick auf die Zeit nach 1945, in Osten-Sacken, P von der Osten-Sacken (Hrsg), Das missbrauchte Evangelium: Studien zu Theorie und Praxis der Thüringer Deutschen Christen, 280-312. Berlin: Institut Kirche und Judentum. (Studien zu Kirche und Israel 20.)

Osten-Sacken, P von der 2002b. „Die große Lästerung“: Beobachtungen zur Gründung des Eisenacher Instituts und zeitgenössische Dokumente zur kritischen Würdigung seiner Arbeit sowie zur Beurteilung Walter Grundmanns, in Osten-Sacken, hrsg. P von der Osten-Sacken, Das missbrauchte Evangelium: Studien zu Theorie und Praxis der Thüringer Deutschen Christen, 313-347. Berlin: Institut Kirche und Judentum. (Studien zu Kirche und Israel 20.)

Pearson, B 1995. The Gospel according to the Jesus Seminar. Religion 25, 317-338.

Pohlmann, H 1943. Der prophetische und der jesuanische Gottesgedanke, in Grundmann, W (Hrsg), Germanentum, Christentum und Judentum: Studien zur Erforschung ihres gegenseitigen Verhältnisses, 301-346. Leipzig: Verlag Georg Wigand.

Poliakov, L \& Wulf, H 1959. Das Dritte Reich und seine Denker. Berlin: Arani.

Renan, E 1981 (1863). Das Leben Jesu. Zürich: Diogenes.

Rese, M 1979: Antisemitismus und neutestamentliche Forschung: Anmerkungen zum Thema Gerhard Kittel und die Judenfrage. EvTh 39, 557-570.

Rosenberg, A [1930] 1941. Der Mythus des 20. Jahrhunderts: Eine Wertung der seelisch-geistigen Gestaltenkämpfe unserer Zeit. 2. Ausgabe. München: Hoheneichen. 
Schenk, W 2002. Der Jenaer Jesus in Osten-Sacken, P von der (Hrsg), Das missbrauchte Evangelium: Studien zu Theorie und Praxis der Thüringer Deutschen Christen, 167-279. Berlin: Institut Kirche und Judentum. (Studien zu Kirche und Israel 20.)

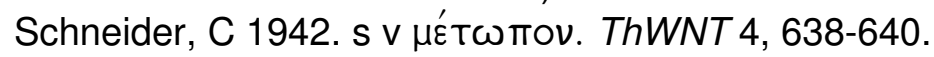

Schulz, A \& Wolfes, M 2001, s v Artur Dinter. BBKL 18, 350-360.

Schwankl, O 1995. s $v$ Karl Ludwig Schmidt. BBKL 9, 461-463.

Schweitzer, A 1984. Die Geschichte der Leben-Jesu-Forschung. 9. Ausgabe. Tübingen: Mohr.

Siegele-Wenschkewitz, L 1978. Die Evangelisch-Theologische Fakultät Tübingen in den Anfangsjahren des Dritten Reichs. ZThK Beiheft 4, 53-80.

Siegele-Wenschkewitz, L 1980. Neutestamentliche Wissenschaft vor der Judenfrage: Gerhard Kittels Arbeit im Wandel deutscher Geschichte. München: Kaiser. (TEH NF 208.)

Siegele-Wenschkewitz, L 1982. Mitverantwortung und Schuld der Christen im Holocaust, EvTh 42, 171-90.

Soden, H von [1904] 1909. Die wichtigsten Fragen im Leben Jesu. 2. Ausgabe. Berlin.

Stauffer, E 1933. Unser Glaube und die Geschichte: Zur Begegnung zwischen Kreuz un Hakenkreuz. Berlin: Furche. (Stimmen aus der deutschen christlichen Studentenbewegung 86.)

Stauffer, E 1938. Die urchristliche Gottestatsache und ihre Auseinandersetzung mit dem Gottesbegriff des Judentums. ThWNT 3, 91-93.

Stauffer, E 1982. Jesus: Geschichte und Verkündigung. ANRW II.25.1, 3-130.

Thomas, C 1997. s v Antijudaismus. Lexikon der jüdisch-christlichen Begegnung: Hintergrunde - Klärungen - Perspektiven, hrsg. von C. Thomas \& U. Petruchowski, 9-11. 2. Ausgabe. Freiburg: Herder.

Vos, J S 1984. Antijudaismus/Antisemitismus im theologischen Wörterbuch zum Neuen Testament. Nederlands Theologisch Tijdschrift 38, 89-110.

Wesseling, K-G 1995. Art Ethelbert Stauffer. BBKL 10, 1245-1250.

Wette, de W M L 1813. Biblische Dogmatik Alten und Neuen Testaments: Oder kritische Darstellung der Religionslehre des Hebraismus, des Judenthums und Urchristentums. Berlin: Realschulbuchhandlung.

Zimmermann, M 1986. Wilhelm Marr: The Patriarch of Anti-Semitism. New York: Oxford University Press. (Studies in Jewish History.) 